\title{
Corrigendum
}

\section{Cellular senescence induced by aberrant MAD2 levels impacts on paclitaxel responsiveness in vitro}

M Prencipe, P Fitzpatrick, S Gorman, M Tosetto, R Klinger, F Furlong, M Harrison, D O'Connor, IB Roninson, J O'Sullivan and A McCann

British Journal of Cancer (2010) 1 02, 456. doi:I0.1038/sj.bjc.6605533 www.bjcancer.com

(c) 2010 Cancer Research UK

Correction to: British Journal of Cancer (2009) 101, 1900-1908. doi:10.1038/sj.bjc.6605419

Upon publication in Volume 101, Number 11, it was noted that the fourth author's name had been spelled incorrectly. We are now happy to correct this - the complete, correct author list is now shown above.

The authors would like to apologise for this mistake. 